\title{
Effects of heavy metals and albumin on lysozyme activity
}

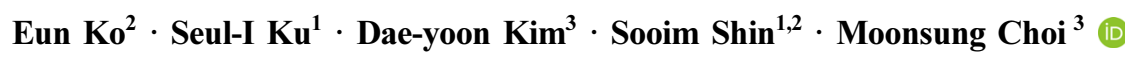

Received: 7 September 2018 / Accepted: 31 October 2018 / Published Online: 31 December 2018

(C) The Korean Society for Applied Biological Chemistry 2018

\begin{abstract}
Lysozyme is an antibacterial enzyme that is found in most of body fluids. Lysozyme in tears plays a primary role in protecting eye from harmful environments; if lysozyme is degraded or inhibited, eyes are likely to be more vulnerable to bacterial infection. In this study, lysozyme activity was evaluated according to varying concentrations of heavy metals, copper, zinc, cobalt and manganese and light metal, calcium that are frequently found in airborne particulate matters and was assayed using a dyequenching lysozyme substrate, Micrococcus lysodeikticus. Less fluorescence intensity was observed with increasing amounts of copper, zinc, manganese and cobalt but not with calcium suggesting that these metals have some affinity with lysozyme and inhibit lysozyme activity. When albumin, the second most common protein in tears, was added on the reaction of lysozyme and metals, lysozyme activity was partially restored. This finding suggests that the albumin might protect damage caused by metals on lysozyme. To identify whether the decrease in enzymatic activity was related to structural changes of lysozyme, SDS-PAGE was conducted and only with copper did lysozyme show marked
\end{abstract}

Eun Ko and Seul-I Ku are equally contributed.

Sooim Shin $(\triangle)$

E-mail: sooim.shin@jnu.ac.kr

Moonsung Choi $(\bowtie)$

E-mail: mschoi@seoultech.ac.kr

${ }^{1}$ Interdisciplinary Program of Bioenergy and Biomaterials Graduate School (BK21 Plus Program), College of Engineering, Chonnam National University, Gwangju 61186, Republic of Korea

${ }^{2}$ Department of Bioengineering and Biotechnology, College of Engineering, Chonnam National University, Gwangju 61186, Republic of Korea

${ }^{3}$ Department of Optometry, College of Energy and Biotechnology, Seoul National University of Science and Technology, Seoul 01811, Republic of Korea

This is an Open Access article distributed under the terms of the Creative Commons Attribution Non-Commercial License (http://creativecommons. org/licenses/by-nc/3.0/) which permits unrestricted non-commercial use, distribution, and reproduction in any medium, provided the original work is properly cited. smearing bands on the SDS-gel, meaning that copper degraded lysozyme consistent with the sharpest activity decrease.

Keywords Albumin - Heavy Metals - Lysozyme activity

\section{Introduction}

Industrial development has resulted in serious environmental problems and heavy metals in particulate matter (PM), are considered one of the main causative factors for environmental problems; heavy metals are defined as metals with specific density above 4.0. Some such as copper, calcium and zinc are essential for biological metabolism, but they can be severely toxic above the required amounts when they accumulate in the body. Cadmium, lead, mercury in air, for example, bind to and modify a number of cellular factors, inhibiting cell growth [1]. Eyes can also be severely affected by heavy metals; corneal or conjunctival damage by heavy metals causes conjunctivitis and dry eyes and the metals' accumulation, especially copper in choroid and retinas causes blindness and sunflower cataract [2].

In addition to eye diseases, heavy metals also affect proteins in tears including lysozyme. Lysozyme is the first physiological enzyme that kills bacteria by hydrolyzing glycosidic bonds in the peptidoglycan of bacterial cell walls [3]. Several types of lysozyme exist in various bodily fluids and serve as the primary protection layer, especially for eyes [3]. Human lysozyme consists of 130 residues and belongs to the c-type class of lysozymes [4]. Functional degradation in lysozyme due to heavy metals makes eyes susceptible to infection.

Heavy metals accumulate after thousands of exposures even when only a small amount of airborne metals is directly exposed to eyes at a given time because there is a study that lead and cadmium accumulate in human ocular tissues when heavy metal concentration was measured in human eyes [5]. For this study four heavy metals and one light metal usually found in PM; copper, zinc, calcium, cobalt and manganese $[6,7]$ were selected to 
examine effects of heavy metals on lysozyme activity. Based on the proteins in tears, various concentrations of all metals were added to chicken egg white lysozyme consisting of 129 amino acids with molecular weight $14.3 \mathrm{kDa}$ and classified as c-type, the same as human lysozyme [8]. Albumin, another main protein in tears, has been added to see how it affects lysozyme activity in the presence of metals. This is the first description to reveal how heavy metals influence lysozyme in the presence of albumin. It is described here that all heavy metals used for the study except for light metal, calcium, reduced lysozyme activity whereas albumin exhibited protective effects on heavy metal-treated lysozymes.

\section{Material and Methods}

\section{Lysozyme activity assay using fluorescence}

Copper (II) sulfate (Sigma Aldrich, St. Louis, MO, USA), zinc sulfate (Sigma Aldrich), calcium chloride dehydrate (Sigma Aldrich), manganese sulfate (Sigma Aldrich), cobalt (II) chloride hexahydrate (Sigma Aldrich) were dissolved in deionized water. All metals were added in concentrations of 50, 130, 260, and 390 $\mu \mathrm{M}$ to $130 \mu \mathrm{M}$ of chicken egg white lysozyme (Sigma Aldrich) in phosphate buffer saline at $\mathrm{pH} 7.4$ which is consistent with the normal concentration in tears. After the mixture were incubated at $36{ }^{\circ} \mathrm{C}$ for $30 \mathrm{~min}$, the dye-quenching lysozyme substrate, Micrococcus lysodeikticus (EnzCheck Lysozyme Assay Kit from Thermo Fisher Scientific, Hampton, NH, USA) was added to start the reaction. Digestion products from the lysozyme substrate have absorption maxima at $494 \mathrm{~nm}$ and fluorescence emission maxima at $518 \mathrm{~nm}$. The fluorescence intensity was measured at $518 \mathrm{~nm}$ using spectral scanning multimode reader (Varioskan, Thermo Fisher Sceintific, Vantaa, Finland). The same set of experiments was also performed in the presence of $3 \mu \mathrm{M}$ of albumin which is consistent with the normal concentration in tears. Aliquots of the above reactions were assessed by $12 \%$ SDS-PAGE at $100 \mathrm{~V}$ for $100 \mathrm{~min}$.

All experiments were repeated three times. Each fluorescence intensity from metal-treated lysozyme activity was normalized against no metal-treated lysozyme activity. Three replicate values were entered in side by side sub-columns and plot mean and error.

\section{Results and Discussion}

Normal concentration of metal in atmospheric PM was $<2 \mu \mathrm{M}$. When the concentration of 2 to $30 \mu \mathrm{M}$ of metals was treated to lysozyme, no significant effect was observed. It should be considered that eyes are directly exposed to atmospheric PM at a given time. Therefore, all metals in concentrations of 50, 130, 260, and $390 \mu \mathrm{M}$ were added to $130 \mu \mathrm{M}$ of chicken egg white lysozyme which is consistent with the normal concentration in tears.
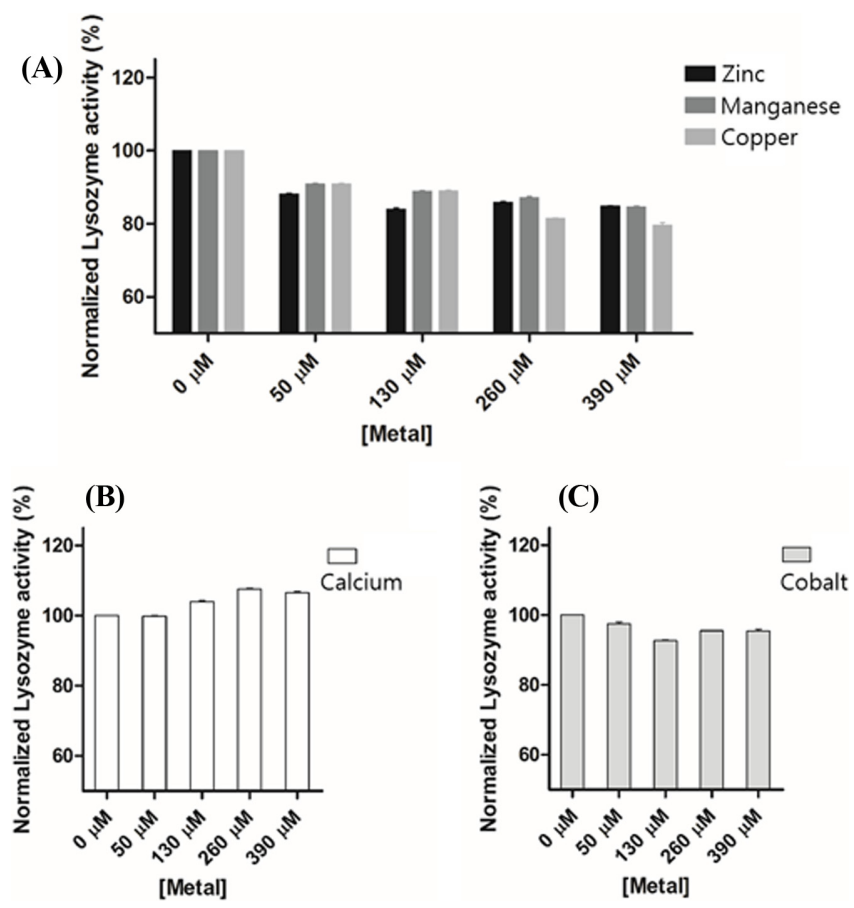

Fig. 1 Lysozyme activity with metals. Catalytic lysozyme activity was measured at different concentrations of zinc, manganese and copper (A), calcium (B) and cobalt (C)

Lysozyme activity decreased sequentially with increasing copper concentration until $390 \mu \mathrm{M}$ (Fig. 1A). The presence of albumin maintained lysozyme activity (Fig. 2A). Severe SDS-PAGE smearing bands copper-added lysozyme demonstrated reduced enzymatic activity caused by structural degradation (Fig. 3). In the presence of albumin, relatively decreased smearing was observed on the SDS gel at higher concentrations of copper (Fig. 3).

The irreversible effect of copper on lysozyme has been studied in a variety of contexts [9], and finds are consistent that copper reduces catalytic lysozyme function by approximately $80 \%$ at $390 \mu \mathrm{M}$ and that structural lysozyme stability decreases as well (Fig. 1A). $\mathrm{Cu}^{2+}$ binds to residues Glu35 and Asp52 located at the catalytic site [9] and degrades overall construction as seen in the severe smearing on SDS gel (Fig. 3). However, fluorescence, the marker for cell wall degradation used as a substrate, in contrast increased with copper concentrations above $400 \mu \mathrm{M}$. It assumed that this reaction takes place because of the direct toxicity of copper on cell walls. When copper forms a complex with cell wall, polysaccharides and hydroxyl ions occur and causes polysaccharide solubilization [10]. To determine the exact relationship between heavy metals and lysozyme, in this study the effects were observed metal concentrations under $400 \mu \mathrm{M}$. It should be noted that there was no effect on substrates' cell wall destruction by divalent metal ions with $<400 \mu \mathrm{M}$ because increases of fluorescence intensity were not detected at the points under $400 \mu \mathrm{M}$.

The other metals, except for calcium (Fig. 1B) also inhibited lysozyme activity but not by as much as the reduction with added 

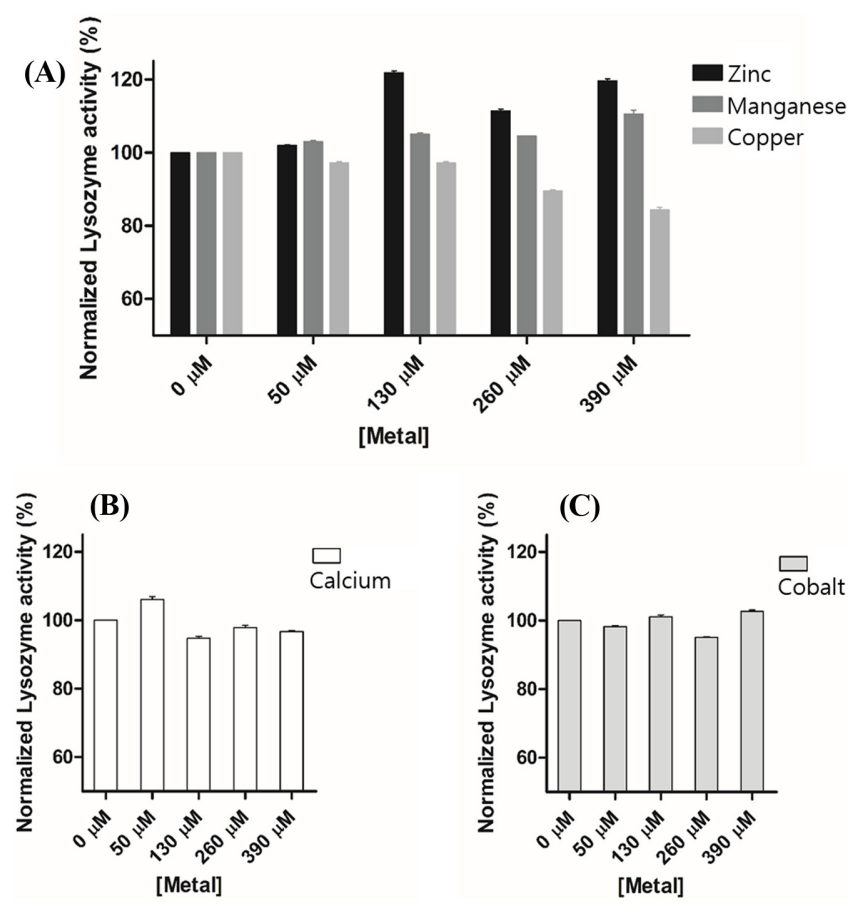

Fig. 2 Lysozyme activity at varying concentrations of metals in the presence of albumin. Catalytic lysozyme activity was measured at different concentrations of zinc, manganese and copper (A), calcium (B) and cobalt $(\mathrm{C})$

copper on lysozyme (Fig. 1C). Manganese and zinc degraded catalytic function similarly, approximately $85 \%$ at $390 \mu \mathrm{M}$ (Fig. 1A). These metals are known as interacting lysozyme or lysozymelike enzyme secreted from starfish [11-13]. The binding of manganese and zinc on the active site of lysozyme might prevent lysozyme activity. Cobalt exhibited weak binding affinity to lysozyme at the residue Asp52 [14-16] compared with manganese [17], resulting in relatively little activity reduction (Fig. 1C). No smearing bands on SDS gel were observed for zinc, calcium, cobalt or manganese (data not shown) in contrast with the bands for copper-treated in lysozyme. That is, there was little structural damage from those metals, and the decreases in observed activity were not related to structural damages [16].

The presence of albumin clearly helped to maintain lysozyme activity (Fig. 2). Albumin serves as a carrier for a variety of nutrients, metabolites and metals. Four different metal binding sites are described as ATCUN motif, site A, site B and reduced Cys34 [18]. Meanwhile, copper, zinc, calcium, and cobalt are known to bind with albumin $[18,19]$. Metals may compete to bind on lysozyme or albumin, and thus lysozyme activity was inhibited less in the presence of albumin than in its absence. When zinc and manganese reacted with lysozyme, activity increased with albumin suggesting something happened among the complexes of zinc and manganese and albumin plus lysozyme. It requires to prove in further.

Interestingly, lysozyme activity increased with calcium (Fig. 1B). Higher concentrations of calcium, increased the lysozyme activity. The presence of albumin in the calcium-treated lysozyme didn't make any remarkable difference in activity (Fig. 2B), even on SDS-PAGE analysis. Calcium appeared not to influence either lysozyme activity or structure. It is thought that fluorescence increase not because calcium interacts with lysozyme but it destabilizes cell walls. Calcium is in fact used to transforming Micrococcus lysodeikticus and destabilize cell walls [20]. When albumin is added, calcium binds to the albumin at site B [18], and only lysozyme catalyze the cell walls; as result, fluorescence

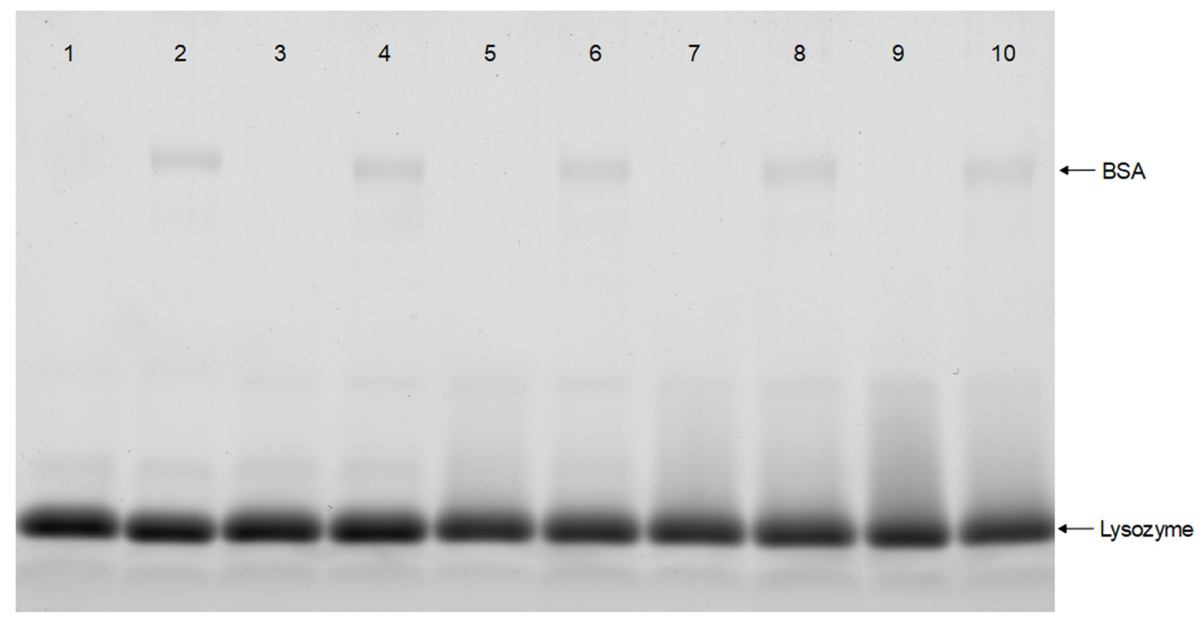

Fig. 3 SDS-PAGE of copper-treated lysozyme in the absence and presence of albumin. Lysozyme samples were subjected to 12\% SDS-PAGE. Lane 1, $130 \mu \mathrm{M}$ of Lysozyme; Lane 2, $130 \mu \mathrm{M}$ of lysozyme with $3 \mu \mathrm{M}$ of albumin; Lane 3, $130 \mu \mathrm{M}$ of lysozyme with $50 \mu \mathrm{M}$ of copper; Lane $4,130 \mu \mathrm{M}$ of lysozyme with $50 \mu \mathrm{M}$ of copper and $3 \mu \mathrm{M}$ of albumin; Lane $5,130 \mu \mathrm{M}$ of lysozyme with $130 \mu \mathrm{M}$ of copper; Lane $6,130 \mu \mathrm{M}$ of lysozyme with $130 \mu \mathrm{M}$ of copper and $3 \mu \mathrm{M}$ of albumin; Lane 7, $130 \mu \mathrm{M}$ of lysozyme with $260 \mu \mathrm{M}$ of copper; Lane $8,130 \mu \mathrm{M}$ of lysozyme with $260 \mu \mathrm{M}$ of copper and $3 \mu \mathrm{M}$ of albumin; Lane $9,130 \mu \mathrm{M}$ of lysozyme with $390 \mu \mathrm{M}$ of copper; Lane $10,130 \mu \mathrm{M}$ of lysozyme with $390 \mu \mathrm{M}$ of copper and $3 \mu \mathrm{M}$ of albumin 
remains approximately $100 \%$ regardless of calcium concentration. PM has long been studied in a variety of fields and is closely related to daily life and health. The findings from this study reflect this trend and particularly regarding the effects of heavy metals on lysozyme. There have been many studies on the interaction between metals and proteins, but this is the first attempt to reveal how heavy metals influence lysozyme in the presence of albumin. The results in here indicated that albumin might primarily interact with heavy metals for the lysozyme activity in situ.

Acknowledgments This work was supported by Business for Cooperative R\&D between Industry, Academy, and Research Institute funded Korea Small and Medium Business Administration in 2018(C0541528) and funded by the Korea Ministry of Environment (MOE) as "the Environmental Health Action Program.” (2016001370001)

\section{References}

1. Jaishankar M, Tseten T, Anbalagan N, Mathew BB, Beeregowda KN (2014) Toxicity, mechanism and health effects of some heavy metals. Interdiscip Toxicol 7: 60-72

2. Erie JC, Butz JA, Good JA, Erie EA, Burritt MF, Cameron JD (2005) Heavy metal concentrations in human eyes. Am J Ophthalmol 139: 888 893

3. Callewaert L, Michiels CW (2010) Lysozymes in the animal kingdom. J Biosci 35: 127-160

4. Merlini G, Bellotti V (2005) Lysozyme: a paradigmatic molecule for the investigation of protein structure, function and misfolding. Clin Chim Acta 357: 168-172

5. Erie JC, Butz JA, Good JA, Erie EA, Burritt MF, Cameron JD (2005) Heavy metal concentrations in human eyes. Am J Ophthalmol 139: 888893

6. Quiterio SL, Da Silva CRS, Arbilla G, Escaleira V (2004) Metals in airborne particulate matter in the industrial district of Santa Cruz, Rio de
Janeiro, in an annual period. Atmos Environ 38: 321-331

7. Zereini F, Alt F, Messerschmidt J, Wiseman C, Feldmann I, Von Bohlen A, MÜller J, Liebl K, PÜttmann W (2005) Concentration and distribution of heavy metals in urban airborne particulate matter in Frankfurt am Main, Germany. Environ Sci Technol 39: 2983-2989

8. Croguennec T, Nau F, Molle D, Le Graet Y, Brule G (2000) Iron and citrate interactions with hen egg white lysozyme. Food Chem 68: 29-35

9. Jing M, Song W, Liu R (2016) Binding of copper to lysozyme: Spectroscopic, isothermal titration calorimetry and molecular docking studies. Spectrochim Acta Part A: Mol Biomol Spec 164: 103-109

10. Fry SC, Miller JG, Dumville JC (2002) A proposed role for copper ions in cell wall loosening. Plant Soil 247: 57-67

11. Ikeda K, HAMAGUCHI K (1973) Interactions of $\mathrm{Mn} 2+, \mathrm{Co} 2+$, and $\mathrm{Ni} 2+$ ions with hen egg-white lysozyme and with its $\mathrm{N}$ acetylchitooligosaccharide complexes. J Biochem 73: 307-322

12. Li SJ (2006) Structural details at active site of hen egg white lysozyme with di-and trivalent metal ions. Biopolymers 81 : 74-80

13. Stabili L, Pagliara P (2009) Effect of zinc on lysozyme-like activity of the seastar Marthasterias glacialis (Echinodermata, Asteroidea) mucus. J Invertebr Pathol 100: 189-192

14. Jyotsna T, Bandara K, Kumar CV (2008) Inorganic photochemical protein scissors: photocleavage of lysozyme by Co (III) complexes. Photoch Photobio Sci 7: 1531-1539

15. Kumar CV, Thota J (2005) Photocleavage of lysozyme by cobalt (III) complexes. Inorg chem 44: 825-827

16. Yonath A, Smilansky A, Sharon N (1974) X-ray crystallographic study of binding of cobalt ion to hen egg-white lysozyme. FEBS letters 49: $178-180$

17. Gallo A, Swift T, Sable H (1971) Magnetic resonance study of the Mn2+-lysozyme complex. Biochem Bioph Res Co 43: 1232-1238

18. Lu J, Stewart AJ, Sadler PJ, Pinheiro TJT, Blindauer CA (2008) Albumin as a zinc carrier: properties of its high-affinity zinc-binding site. Biochem Soc T 36: 1317-1321

19. Bal W, Soko ${ }^{3}$ owska M, Kurowska E, Faller P (2013) Binding of transition metal ions to albumin: sites, affinities and rates. Biochim Biophys Acta Gen Subj 1830: 5444-5455

20. Kloos WE (1969) Factors affecting transformation of Micrococcus lysodeikticus. J Bacteriol 98: 1397-1399 